\title{
Phylogenomics of fescue grass-derived fungal endophytes based on selected nuclear genes and the mitochondrial gene complement
}

\author{
Piyumi N Ekanayake ${ }^{1,2,3}$, Maia Rabinovich ${ }^{1,2}$, Kathryn M Guthridge ${ }^{1,2}$, German C Spangenberg ${ }^{1,2,3}$,
} John W Forster ${ }^{1,2,3^{*}}$ and Timothy I Sawbridge ${ }^{1,2,3}$

\begin{abstract}
Background: Tall fescue and meadow fescue are important as temperate pasture grasses, forming mutualistic associations with asexual Neotyphodium endophytes. The most frequently identified endophyte of Continental allohexaploid tall fescue is Neotyphodium coenophialum, while representatives of two other taxa (FaTG-2 and FaTG-3) have been described as colonising decaploid and Mediterranean hexaploid tall fescue, respectively. In addition, a recent study identified two other putatively novel endophyte taxa from Mediterranean hexaploid and decaploid tall fescue accessions, which were designated as uncharacterised Neotyphodium species (UNS) and FaTG-3-like respectively. In contrast, diploid meadow fescue mainly forms associations with the endophyte taxon Neotyphodium uncinatum, although a second endophyte taxon, termed N. siegelii, has also been described.
\end{abstract}

Results: Multiple copies of the translation elongation factor 1-a (tefA) and $\beta$-tubulin (tub2) 'house-keeping' genes, as well as the endophyte-specific perA gene, were identified for each fescue-derived endophyte taxon from whole genome sequence data. The assembled gene sequences were used to reconstruct evolutionary relationships between the heteroploid fescue-derived endophytes and putative ancestral sub-genomes derived from known sexual Epichloë species. In addition to the nuclear genome-derived genes, the complete mitochondrial genome (mt genome) sequence was obtained for each of the sequenced endophyte, and phylogenetic relationships between the $\mathrm{mt}$ genome protein coding gene complements were also reconstructed.

Conclusions: Complex and highly reticulated evolutionary relationships between Epichloë-Neotyphodium endophytes have been predicted on the basis of multiple nuclear genes and entire mitochondrial protein-coding gene complements, derived from independent assembly of whole genome sequence reads. The results are consistent with previous studies while also providing novel phylogenetic insights, particularly through inclusion of data from the endophyte lineage-specific gene, as well as affording evidence for the origin of cytoplasmic genomes. In particular, the results obtained from the present study imply the possible occurrence of at least two distinct E. typhina progenitors for heteropoid taxa, as well the ancestral contribution of an endophyte species distinct from (although related to) contemporary E. baconii to the extant hybrid species. Furthermore, the present study confirmed the distinct taxonomic status of the newly identified fescue endophyte taxa, FaTG-3-like and UNS, which are consequently proposed to be renamed FaTG4 and FaTG5, respectively.

Keywords: Festuca, Pasture grass, Whole genome sequencing, PerA, TefA, Tub2

\footnotetext{
* Correspondence: john.forster@depi.vic.gov.au

${ }^{1}$ Department of Environment and Primary Industries, Biosciences Research

Division, AgriBio, the Centre for AgriBioscience, 5 Ring Road, Bundoora,

Victoria 3086, Australia

${ }^{2}$ Dairy Futures Cooperative Research Centre, Bundoora, Australia

Full list of author information is available at the end of the article
}

\section{Biomed Central}

(c) 2013 Ekanayake et al.; licensee BioMed Central Ltd. This is an open access article distributed under the terms of the Creative Commons Attribution License (http://creativecommons.org/licenses/by/2.0), which permits unrestricted use, distribution, and reproduction in any medium, provided the original work is properly cited. 


\section{Background}

Neotyphodium endophytes are asexual fungal species that form mutualistic interactions with a number of coolseason grasses, including ryegrasses (Lolium spp.) and fescues (Festuca spp.). Endophytes are disseminated through dispersal of plant seeds and obtain nutrition and protection from the host plant, while conferring superior persistence characteristics on the grass, such as improvements of mineral uptake and drought tolerance [1,2]. Furthermore, symbiotic fungal endophytes provide protection from vertebrate and invertebrate herbivores to the host plant through production of bioprotective alkaloids. To date, four major classes of alkaloids have been identified from endophyte infection of host grasses [3]: peramine and lolines, which deter invertebrate predation [4-6], and indol-diterpenes and ergot alkaloids, which are toxic to grazing vertebrates such as ruminant livestock $[7,8]$. Tall fescue (Festuca arundinacea Schreb. syn. Lolium arundinaceum [Schreb.] Darbysh.) and meadow fescue (Festuca pratensis Huds. [syn. Lolium pratense (Huds.) Darbysh.]) are two fescue taxa that are particularly important as temperate pasture grasses, and form associations with Neotyphodium endophytes. Tall fescue exhibits multiple ploidy level variants from tetraploid to decaploid $[9,10]$. Furthermore, within the hexaploid type, the commonly cultivated Continental and Mediterranean morphotypes have been deduced to arise from differing diploid progenitor genomes [11]. The most frequently identified endophyte of Continental allohexaploid tall fescue is Neotyphodium coenophialum (Morgan-Jones et Gams) Glenn, Bacon et Hanlin [12], while representatives of two other taxa, Festuca arundinacea taxonomic group 2 (FaTG-2) and Festuca arundinacea taxonomic group 3 (FaTG-3), have been described as colonising decaploid and Mediterranean hexaploid tall fescue, respectively $[9,13]$. In addition, a recent study based on simple sequence repeat (SSR) genotyping identified two other putatively novel endophyte taxa from Mediterranean hexaploid and decaploid tall fescue accessions, which were designated as uncharacterised Neotyphodium species (UNS) and FaTG-3-like [9] (later named as FaTG-4:[14]) respectively. In contrast, diploid meadow fescue mainly forms associations with the endophyte taxon Neotyphodium uncinatum (Gains, Petrini and Schmidt) Glenn, Bacon, Price and Hanli, although a second endophyte taxon, termed $N$. siegelii, has also been described [15].

All of these previously characterised and novel endophyte taxa of tall and meadow fescue exhibit heteroploid genome constitutions, based either on presence of multiple copies of known gene sequences [14,16-18] or generation of multiple PCR amplicons from specific SSR loci $[9,19]$. On this basis, such endophytes have been proposed to originate from sexual Epichloë species through a series of interspecific hybridisation events. Although the probable origins of several Neotyphodium species are believed to be well understood, those of the novel UNS and FaTG-3-like taxa are yet to be determined. In addition, the degree of resolution of such phylogenomic analysis is a function of both the number and nature of the DNA sequences used to perform such studies.

Nuclear protein-coding gene sequences have been employed in previous studies of fungal endophytes to elucidate evolutionary relationships at the intraspecific and interspecific levels, through phylogenetic analysis of partial sequences representing orthologous intronic regions of the translation elongation factor 1-a (tefA), $\beta$-tubulin (tub2) and actin (act1) genes [14,18,20,21]. However, each of these genes encodes proteins that control essential functions in eukaryotic genomes, and are hence not exclusive to either fungal species or, indeed, Neotyphodium endophytes. Phylogenetic analysis of gene sequences that are specific to the Epichloë-Neotyphodium lineage could hence provide higher resolution of the phylogenetic affinities between sexual and asexual endophyte taxa. The perA gene catalyses synthesis of the invertebrate deterrent alkaloid peramine [6], and hence provides an ideal candidate. In previous studies, the number of multiple perA gene copies present in heteroploid endophytes has been shown to be consistent with proposed hybrid origins, irrespective of peramine production levels [6]. In addition, as a presumably dispensable gene, perA gene exhibits a higher rate of molecular evolution than the essential tefA and tub2 genes [22], providing the capacity to resolve close taxonomic relationships. In a previous study, phylogenetic analysis based on sequenced PCR amplicons from the perA gene was performed for a selected set of fescue-derived endophytes [23]. However, inclusion of a larger number of additional perA genes, including those from putative progenitor Epichloë species, would be expected to improve the resolution of analysis and obtain a deeper understanding of EpichloëNeotyphodium phylogenomics.

In addition to nuclear genes, sequence variation within the mitochondrial $(\mathrm{mt})$ genome may be used to fully interpret the interspecific hybridisation process by which heteroploid endophytes are believed to have arisen. Following two-way interspecific hybridisation of filamentous fungi, segregation of $\mathrm{mt}$ genomes is believed to result in pure unmixed derivatives, although the temporary presence of heteroplasmons may permit intergenomic recombination events [24]. Mt DNA also offers an advantage in terms of copy number, which has been estimated to range from ten to several thousand per cell $[25,26]$. Consequently, depth-of-coverage related to mt DNA in a whole genome sequencing dataset will be considerably higher than for genomic regions, increasing confidence of analysis. Furthermore, comparisons of molecular evolution between the nuclear and mitochondrial genomes of fungi have revealed accelerated rates in the latter [27], potentially 
increasing the capacity to discriminate between closely related taxa.

The present study describes phylogenetic analysis of fescue-derived endophytes based on three nuclear proteincoding genes (tefA, tub2, perA) and the complete proteincoding gene complement of the mt genome. This study has provided confirmation of known relationships and additional novel insights, due to the higher resolution permitted by multiple gene analysis. The majority of previous studies of Epichloë-Neotyphodium species have been based on sequences from PCR amplicons of partial gene sequences. In contrast, the present study describes, for the first time, identification and use of complete sequences from the relevant genes solely derived from whole genome sequence datasets.

\section{Methods}

\section{Endophyte isolates and DNA extraction}

Phylogenetic analysis was performed on 16 endophyte isolates (Table 1) representing the known taxa $N$. coenophialum, $N$. uncinatum, FaTG-2 and FaTG-3, as well as the two putative distinct taxa previously designated as FaTG-3-like and UNS [9]. Genomic DNA was extracted

Table 1 Endophyte isolates used for phylogenetic analysis

\begin{tabular}{|c|c|c|c|c|}
\hline $\begin{array}{l}\text { Endophyte } \\
\text { isolate }\end{array}$ & $\begin{array}{l}\text { Species or } \\
\text { taxon }\end{array}$ & Host species & Origin & Source* \\
\hline E34 & N. coenophialum & F. arundinacea & & $\mathrm{RBG}$ \\
\hline NEA14 & N. coenophialum & F. arundinacea & France & NZA \\
\hline NEA16 & N. coenophialum & F. arundinacea & France & $N Z A$ \\
\hline NEA20 & N. coenophialum & F. arundinacea & France & $\mathrm{NZA}$ \\
\hline NEA22 & N. coenophialum & F. arundinacea & Spain & $\mathrm{NZA}$ \\
\hline NEA21 & FaTG-3\# & F. arundinacea & Morocco & $\mathrm{NZA}$ \\
\hline NEA23 & FaTG-3 & F. arundinacea & Tunisia & NZA \\
\hline NEA17 & $\mathrm{FaTG}-2^{\$}$ & F. arundinacea & Spain & NZA \\
\hline NEA32 & FaTG-2 & F. arundinacea & Morocco & NZA \\
\hline NEA19 & UNS & F. arundinacea & Algeria & NZA \\
\hline NEA18 & UNS & F. arundinacea & Sardinia & $\mathrm{NZA}$ \\
\hline E81 & N. uncinatum & F. pratensis & & $\mathrm{RBG}$ \\
\hline NEA33 & FaTG-3-like & F. arundinacea & Morocco & NZA \\
\hline 9707 & E. baconii & Agrostis tenuis & Switzerland & ETH Zürich \\
\hline 9340 & E. typhina & Poa pratenis & Switzerland & ETH Zürich \\
\hline 9636 & E. typhina & Poa trivialis & Switzerland & ETH Zürich \\
\hline SE & N. Iolii & $\begin{array}{l}\text { Lolium } \\
\text { perenne }\end{array}$ & $\begin{array}{l}\text { New } \\
\text { Zealand }\end{array}$ & DEPI \\
\hline
\end{tabular}

*ETH Zürich: Eidgenössische Technische Hochschule Zürich (Swiss Federal Institute of Technology, Zürich, Switzerland); NZA: New Zealand Agriseeds Ltd, Christchurch, New Zealand; RBG: Royal Barenbrug Group, Nijmegen-Noord, Netherlands; DEPI: Department of Environment and Primary Industries, Victoria, Australia.

${ }^{\$}$ FaTG-2: Festuca arundinacea taxonomic group 2.

${ }^{\#}$ FaTG-3: Festuca arundinacea taxonomic group 3. from lyophilized mycelia by cetyltrimethylammonium bromide (CTAB) extraction [28], and the quality and quantity of the DNA was assessed by both agarose gel electrophoresis and specific absorbance measurements using the NanoDrop 2000 Spectrophotometer (Thermo Scientific, Waltham, Massachusetts, USA).

\section{Paired-end library preparation and sequencing}

Genomic DNA was fragmented in a Covaris instrument (Woburn, MA, USA) to an average size of 100-900 bp. For each endophyte DNA sample, paired-end libraries with inserts c. $400 \mathrm{bp}$ in size were prepared using the standard protocol (TruSeq DNA Sample Prep V2 Low Throughput: Illumina Inc., San Diego, USA) with pairedend adaptors. Library quantification was performed using the KAPA library quantification kit (KAPA Biosystems, Boston, USA). Paired-end libraries were pooled according to the attached adaptors and sequence analysed using the HiSeq2000 platform (Illumina) following the standard manufacturer's protocol.

\section{Processing and assembly of sequence data}

All generated sequence reads were quality controlled by filtering and trimming of reads based on quality using a custom Python script, which calculates quality statistics, and stores trimmed reads in several fastq files. Data assembly was performed using the Linux-based de novo assembler Velvet ver.1.1.06 [29]. For Velvet assembly, different hash lengths (K-mer sizes) ranging from 39 to 51 were tested as appropriate for different sequence read sets, and the minimum contig length was always defined as $200 \mathrm{bp}$. Values for estimated coverage and coverage cutoff were set to auto.

\section{Assembly of nuclear gene sequences}

Presence and copy number of tub2, tefA, and perA genes (using Genbank accession numbers:tub2: AY722412, tefA: FJ660614, perA: AB205145) in each endophyte genome were initially determined through nucleotide BLAST (Basic Local Alignment Search Tool) [30] analysis using contigs from the optimised Velvet assembly of total reads as the database. In order to assemble each gene copy, matching reads for each reference gene were identified from a database of all trimmed reads from each endophyte genome, through a similarity search using BLAST, defining the E value threshold as 0.1. From this BLAST output, all corresponding paired reads (both forward and reverse) were extracted from the database, and the second reads were reverse-complemented. Each of the first and second reads was concatenated and used as BLASTN queries against a database consisting solely of each reference gene sequence for assembly. From this search, reads that matched in an anti-sense orientation were reverse-complemented in order to orientate the concatenated reads in $5^{\prime}$ - to $3^{\prime}$-orientation 
against the reference gene sequence. Subsequently, reads were separated into two distinct sets (designated read1 and read2) and the two groups were used individually as BLASTN queries against the gene sequence that was to be assembled. The aim of these individual BLAST searches was to estimate positions for each read against the reference database sequence. After assigning positions, each read was padded to the appropriate position along the reference gene sequence using a customised PERL script. The padded read pairs (when both reads were selected from the BLAST output) were then concatenated and saved in FASTA format. Using the graphical multiple sequence editor SeaView [31], the padded reads were manually assembled into the defining gene sequences. Functional sequences were predicted for multiple perA gene copies through translation of each gene sequence using ExPASy online DNA sequence translation tool [32].

\section{Phylogenetic analysis of nuclear genes}

Multiple alignments of the complete gene sequences for each selected gene were performed individually using ClustalW [33] with default parameters. To reconstruct tree topology, parsimony, maximum likelihood (ML) and neighbour-joining (NJ) methods were used as implemented in MEGA 5 [34] with default parameters and 1,000 bootstrap replicates. Gene sequences available in Genbank from related endophyte species were used appropriately, and corresponding accession numbers are provided in each tree diagram. After identification of proposed origin from an individual genome for each gene copy based on the individual gene trees, the three nuclear genes were concatenated in the order tub2-tefA-perA and aligned using ClustalW with the default parameters. For the concatenated multiple sequence alignment, phylogenetic topology was reconstructed using MEGA with default parameters and 1,000 bootstrap replicates. Phylogenetic networks were constructed for aligned concatenated gene sequences using the NeighborNet algorithm [35] on the Nei-Li pairwise distance matrix, and network diagrams were produced using the program SplitsTree4 [36].

\section{Assembly of mitochondrial genomes}

Contigs of mitochondrial $(\mathrm{mt})$ genome origin were initially identified using nucleotide BLAST at an E value threshold of 0.001 through alignment of a database containing all contigs from the optimised Velvet assembly (as described above) against the $\mathrm{mt}$ genome of the $N$. lolii standard endophyte (SE) strain as a reference [37] (Genbank accession number KF906135). For each candidate endophyte, a set of contigs with higher read depth coverage were shown to have a significant match to the reference $\mathrm{mt}$ genome sequence. A cut-off value for read depth coverage of each $\mathrm{mt}$ genome was identified based on the BLAST output, and a second Velvet assembly was performed with assignment of this value as the coverage cut-off value in order to filter contigs derived from the $\mathrm{mt}$ genome. A range of k-mer values were tested, and a final assembly was accepted on the basis of features such as total number of assembled contigs, N50 value and cumulative contig length. For those mt genomes with few (2-5) contigs, ordering was performed with BLASTN (E value threshold of 0.001) based on the pre-existing SE mt genome sequence, and overlapping regions were manually linked. In order to confirm gaps observed in comparison to the SE mt genome, alignment was performed for trimmed reads using the Burrows-Wheeler Alignment (BWA) tool [38] with the maximum number of gap openings set to five. Mapped reads were viewed using Tablet 1.12.02.06 [39], a graphical viewer for sequence alignment. Observed gaps were further confirmed through grouping of observed gap positions within each endophyte species or taxon.

Identification of protein-coding gene sequences was performed using each $\mathrm{mt}$ genome sequence as the query database against the individual mitochondrial protein gene sequences from the clavicipitacean entomopathogenic fungus Metarhizium anisopliae (Genbank accession number NC008068). Identified protein-coding genes were concatenated according to the order observed in the $M$. anisopliae $\mathrm{mt}$ genome.

\section{Phylogenetic analysis of $\mathrm{mt}$ genome protein coding gene complement}

Multiple alignment of concatenated mitochondrial proteincoding gene complements from the 19 endophytes and counterparts in $M$. anisopliae was performed using the M-LAGAN program within the mVISTA on-line suite of computational tools [40], with default parameters. Alignments were manually edited for mis-alignments that may have accumulated due to overlapping gene fragments. To reconstruct the tree topology, parsimony, $\mathrm{ML}$ and $\mathrm{NJ}$ methods were used as implemented in MEGA 5 with default parameters and 1,000 bootstrap replicates. Furthermore, to study the level of identity of each $\mathrm{mt}$ genome protein-coding complement relative to that of $M$. anisopliae, aligned sequences were visualized through use of a VISTA plot [41].

\section{Results}

\section{Identification of individual nuclear gene copies}

Presence of the three nuclear genes (tub2, tefA and perA) was determined for 13 fescue-derived endophyte genomes and all other reference taxa (Epichloë spp. and N. lolii) that were used for this study. The observed number of copies for each gene within each taxon was then determined (Table 2). For each gene, 3 copies were observed within individual $N$. coenophialum genomes, while 2 copies were observed from all other taxa apart from $N$. uncinatum, which contained a single copy of the tub2 gene. Moreover, one of the assembled perA gene copies 
Table 2 Number of gene copies identified from each endophyte taxon represented in the analysis

\begin{tabular}{cccccccc}
\hline & Gene & \multicolumn{5}{c}{ Endophyte taxon } \\
\hline $\begin{array}{c}\text { Observed number of gene } \\
\text { copies for }\end{array}$ & $\boldsymbol{p e r A}$ & N. coenophialum & FaTG-2 & FaTG-3 & FaTG-3 like & UNS & N. uncinatum \\
& $\boldsymbol{t u b 2}$ & 3 & 2 & 2 & 2 & 2 & 2 \\
& $\boldsymbol{t e f A}$ & 3 & 2 & 2 & 2 & 2 \\
\end{tabular}

from FaTG-2, FaTG-3 and UNS genomes revealed a common variant structure based on large- to moderatesized deletions (coordinates 1251-1878 bp and 45904918 bp; Figure 1).

\section{Phylogenetic relationships based on nuclear genes}

Phylogenetic relationships were reconstructed based on individual gene sequences of perA, tub2, and tefA genes, as well as the concatenated sequences of all three genes, using parsimony ML and NJ methods (related alignments can be found at URL: http://purl.org/phylo/treebase/ phylows/study/TB2:S14923). All positions containing gaps and missing data were eliminated during each analysis. Corresponding gene-specific DNA sequences from other taxa that were previously deposited in GenBank were included. Similar tree topologies were observed for all three methods, and the most parsimonious phylograms were selected (Figures 2, 3 and 4 and Additional files 1, 2, 3, 4 and 5). The GenBank accession numbers of the nuclear genes derived from fescue-derived endophytes are provided in Additional file 6. Maximum parsimony analysis based on the individual gene sequences of the three genes resolved more than one most parsimonious tree, and so bootstrap consensus trees inferred from 1000 replicates are displayed for each gene. In each phylogram, individuals from the same endophyte taxa were clustered together, and were separated from the Epichloë isolates that were used in the study. Apart from the placement of $E$. baconii and E. amarillans within the perA-and tefA-specific trees, phylogenetic analysis of individual genes resolved similar genomic relationships between endophyte taxa. All major clades that were defined by single gene phylogeny were also strongly supported by the phylogeny of the concatenated perA, tub2, and tefA genes, due to observation of similar tree topology. Maximum parsimony analysis of concatenated genes yielded a single most parsimonious tree with high level of bootstrap support for the majority of the individual branches.
In all instances, the phylogenetic trees were predominantly separated into two major groups representing different Epichloë species. For example, in the tefA genespecific phylogram (Figure 3), Group 1 contained the taxa E. festucae, E. baconii, E. amarillans and E. bromicola, while Group 2 contained E. sylvatica, E. typhina, and $E$. clarkii. Furthermore, individual gene copies from the fescue-derived endophytes were located closely adjacent to the reference E. festucae-, E. bromicola- and E typhina-derived sequences, suggesting affinities to putative sub-genome components of the heteroploid taxa. However, in all instances members of the fescue-derived endophyte ( $N$. coenophialum, FaTG-2, FaTG-3, FaTG-3like and UNS) gene copy 1 (FGC1) clade were not so closely related to sequences from any of the currently included Epichloë endophytes (Figures 2, 3 and 4 and Additional file 2). In the perA-based phylogeny, E. amarillans formed a sister group to FGC1, while addition of a partial gene sequence from E. amarillans to the tefA-based phylogeny generated a separate clade also containing $E$. baconii. Nevertheless, in the absence of E. amarillans, the tub2-and concatenated gene-based analysis placed FGC1 as a sister group to E. baconii.

The genomes of the known heteroploid endophyte taxa $N$. coenophialum, N. uncinatum and FaTG-3 contributed gene copies to both major phylogram groups, consistent with hybrid origins either from one of the relevant Epichloë species, or a closely related taxon. In contrast, the multiple gene copies from FaTG-2 and UNS were located only within Group 1. High levels of similarity between sequences from different endophyte taxa suggested the presence of common sub-genomic components. For instance, N. coenophialum and N. uncinatum genotypes always contributed gene copies that were identical or very closely related to one another, and similar to those from E. typhina. Although N. coenophialum gene copies showed close affinities to those from other fescue endophyte taxa within Group 1, distinct

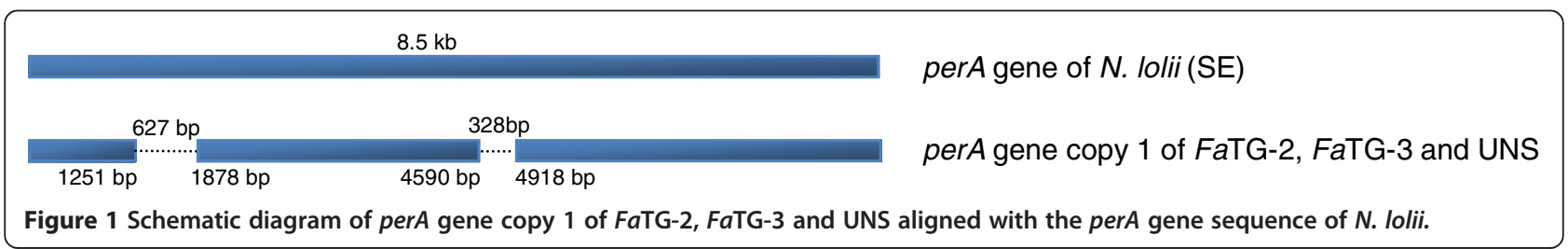




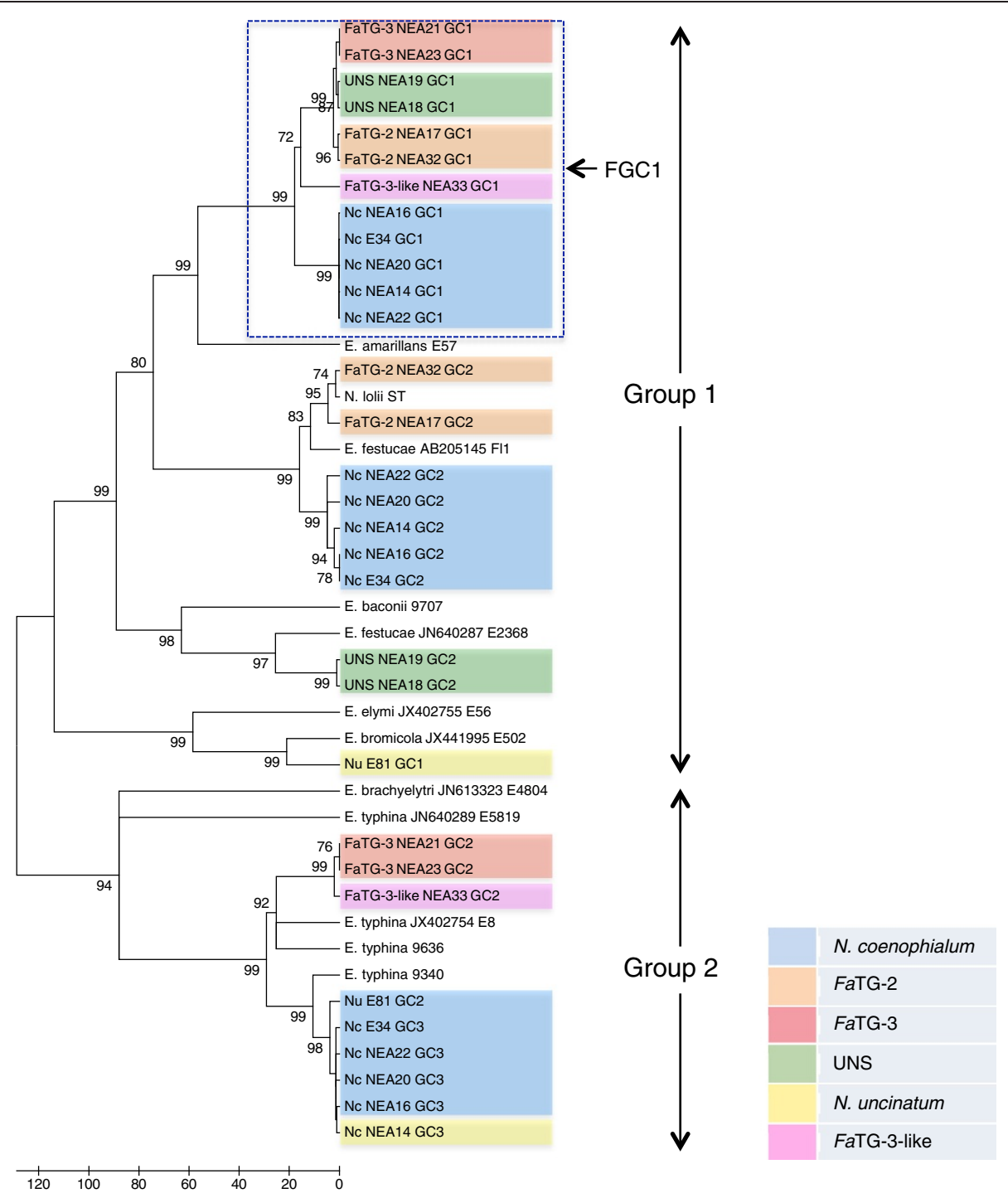

Figure 2 Bootstrap consensus tree generated through parsimony analysis of perA gene sequence among reference endophyte isolates and selected fescue-derived endophytes. Branches with bootstrap values of greater than $70 \%$ from 1000 bootstrap replication are marked next to each branch. Endophyte taxa are colour coded as indicated in the legend. Endophyte taxon abbreviations prior to isolate name are as follows: $\mathrm{Nc}=N$. coenophialum, $\mathrm{Nu}=N$. uncinatum, UNS = uncharacterised Neotyphodium species. The perA gene sequence of $E$. amarillans was derived from whole genome shotgun sequence available in GenBank under accession number: AFRF000000000. The GenBank accession numbers of the perA genes derived from fescue-derived endophytes are provided in Additional file 6.

clusters were generated in all instances. A further point of interest was the close relationships between the FaTG-2derived perA and tefA gene copies and those obtained from both E. festucae and its asexual anamorph, N. lolii.

As an alternative way to explore the reticulated evolutionary relationships between sexual Epichloë progenitor species and heteroploid Neotyphodium endophytes, a phylogenetic network diagram was constructed based on the concatenated nuclear gene sequence (Figure 5). Distinct clusters for asexual endophyte-derived gene copies were formed around the reference E. festucae and E. typhina sequences, corresponding to respective clades in Group 1 and Group 2 of the phylograms, and further supporting the hypothesis of progenitor relationships. Separation of E.baconii from FGC1 gene copies was also consistent with the phylogram structure. The network analysis also served to further demonstrate the differentiation of FaTG-2 and UNS-derived gene copies within the E. festucae-containing clade of the phylograms, despite similarity in both instances to $E$. festucae. Similar results were obtained for FaTG-3- and FaTG-3-like-derived gene copies corresponding to members of FGC1 within the phylograms, and, to a lesser extent, Group 2. 


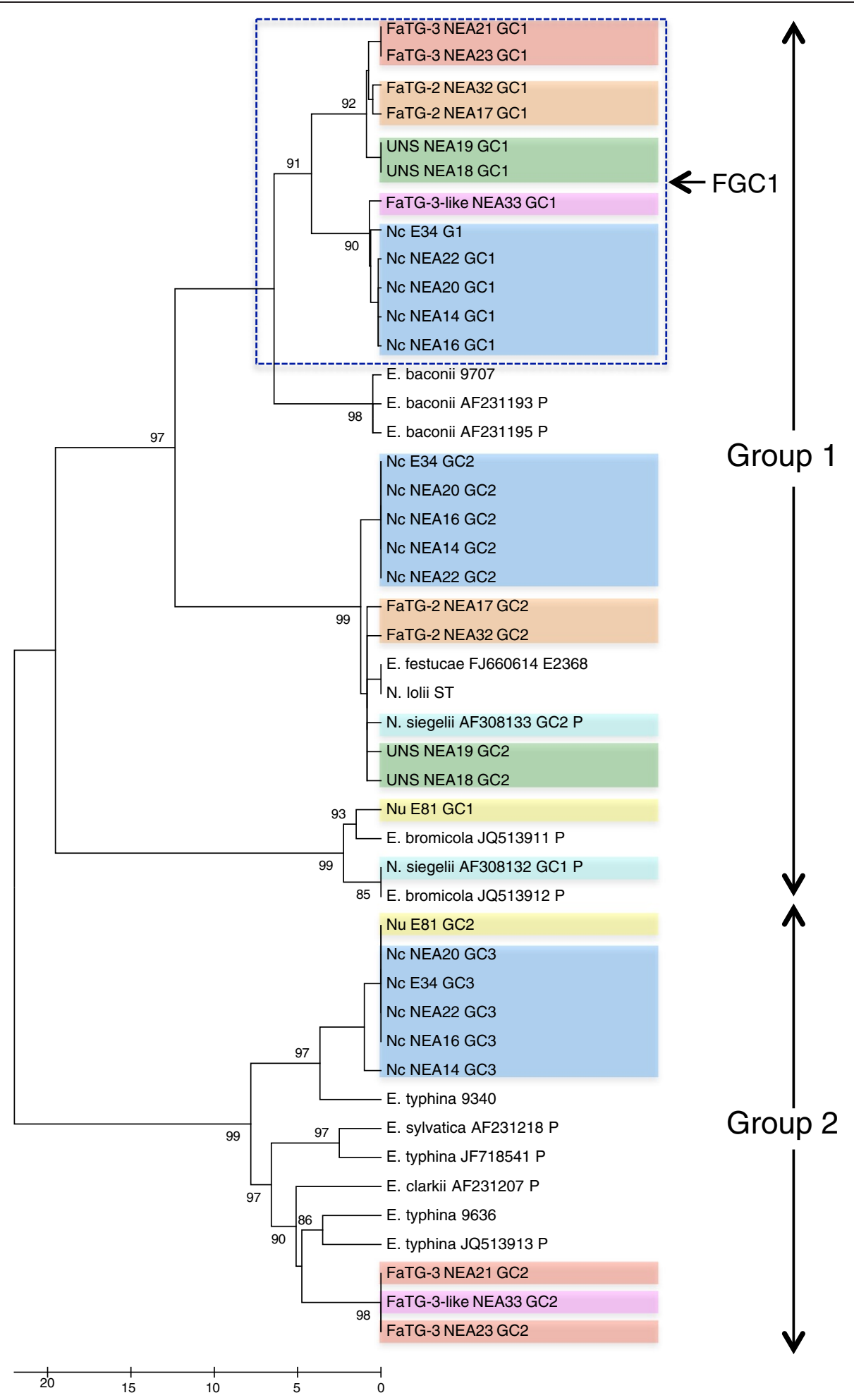

Figure 3 Bootstrap consensus tree generated through parsimony analysis of tefA gene sequence among reference endophyte isolates and selected fescue-derived endophytes. Diagram properties are as described for Figure 2. P indicates partial gene sequences obtained from the Genbank. Accessions numbers are provided adjacent to species name. The GenBank accession numbers of the tefA genes derived from fescue-derived endophytes are provided in Additional file 6. 


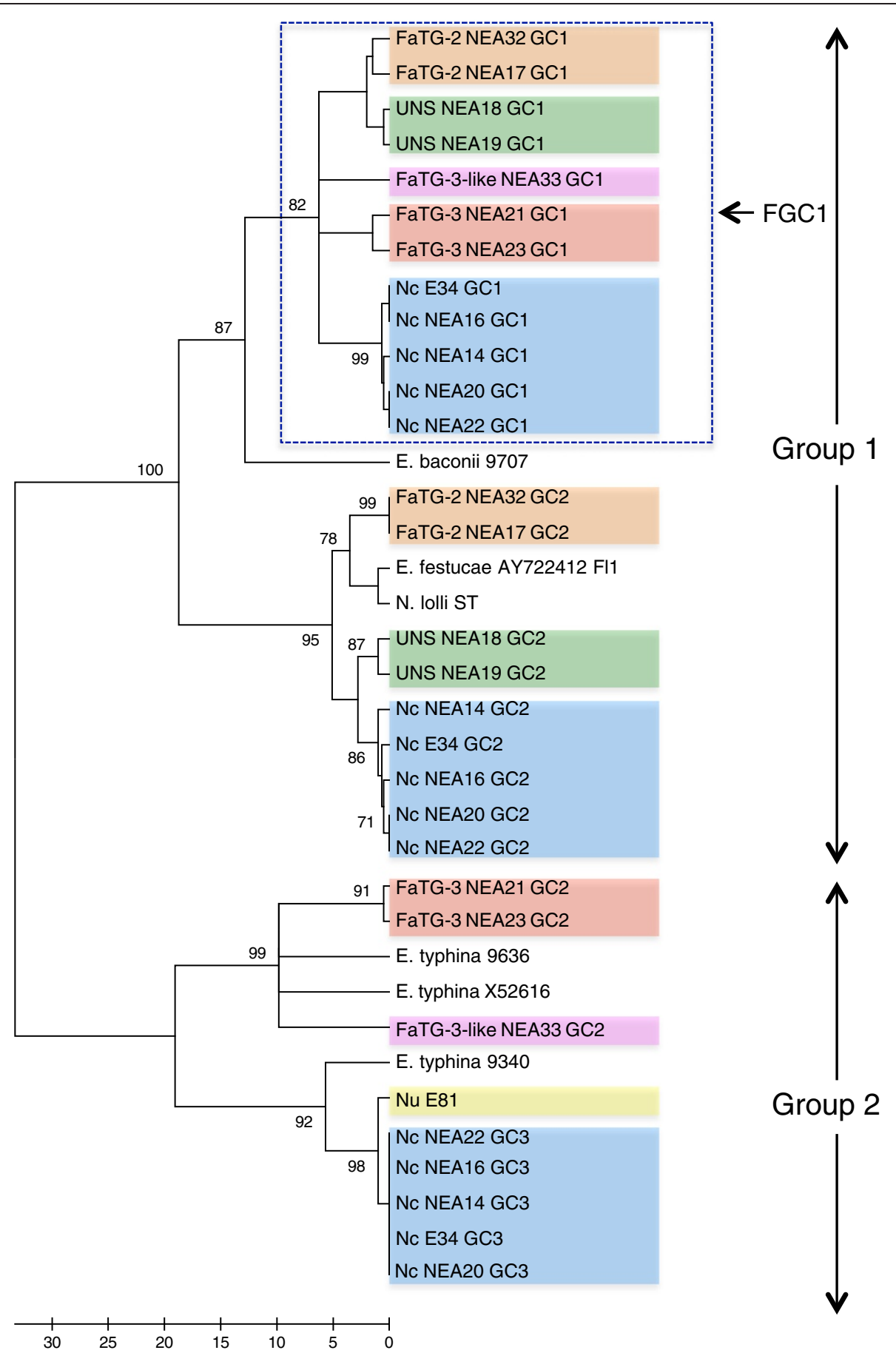

Figure 4 Bootstrap consensus tree generated through parsimony analysis of tub2 gene sequence among reference endophyte isolates and selected fescue-derived endophytes. Diagram properties are as described for Figure 2. The GenBank accession numbers of the tub2 genes derived from fescue-derived endophytes are provided in Additional file 6.

Putative functional gene copies for perA gene were predicted based on sequence translation (to produce an intact biosynthetic enzyme) and assigned to putative progenitor origins based on phylogenetic affinities with Epichloë species that are known to contain such sequences (Table 3). Putative gene functionality was consistent between the predicted sub-genomic components of each taxon. For example, both $E$. festucae- and E. typhina-like perA gene copies (from Group 1 and Group 2) were predicted to be functional for all $N$. coenophialum isolates used for this study. In contrast, the perA gene copy characteristic of FGC1 was predicted to be non-functional for the $N$. 


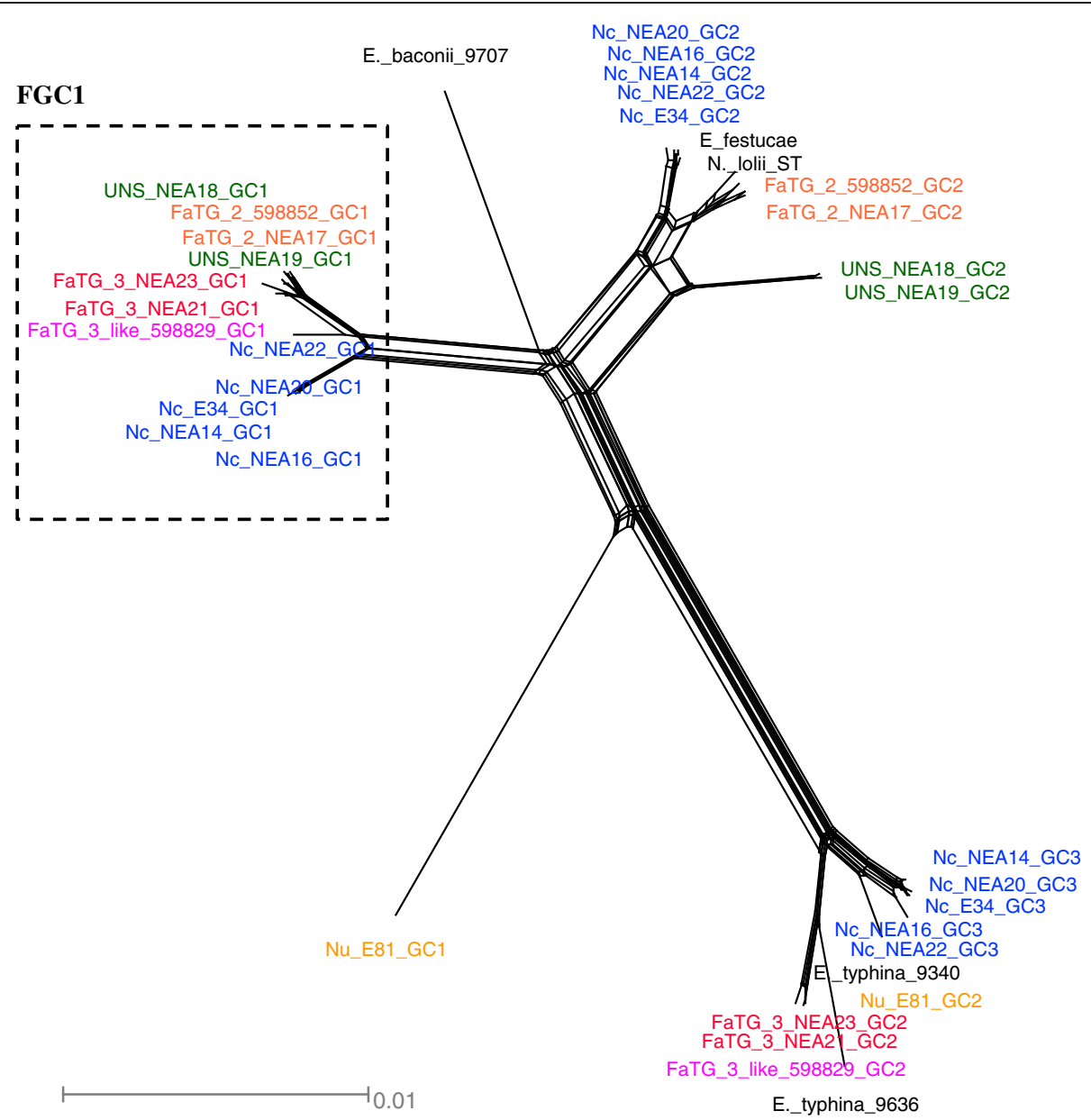

Figure 5 NeighborNet network of relationships between copies of the concatenated tub2, tefA and perA gene sequences from reference endophyte isolates and selected fescue endophytes.

coenophialum, UNS, FaTG-2, FaTG-3, and FaTG-3-like gene copies. Furthermore, predicted gene functionality was also consistent with the results of preliminary alkaloid profile analysis. For example, both perA gene copies of UNS endophytes were predicted to be non-functional, and these endophytes have not been observed to produce peramine in planta (P. Ekanayake, unpublished).

\section{Mitochondrial genome sequence structure}

General structural characteristics for the $19 \mathrm{mt}$ genomes were determined (Table 4), revealing variation of overall size from 51,884 - 96,481 bp. All except E. typhina mt genome sizes varied slightly within a given taxon, larger differences being observed between taxa. All shared the same 13 protein-coding genes arranged in the same order, accounting for $15 \%-28 \%$ of the entire $\mathrm{mt}$ genome, and showing $90 \%$ cumulative sequence similarity to the outgroup species, $M$. anisopliae. In contrast to conservation of the protein-coding components, higher levels of sequence divergence were apparent within the intergenic regions, due to multiple insertion/deletion events when compared to the $N$. lolii SE mt genome that was used as a reference. A further complication in this analysis was the presence of nuclear genome-derived sequences that showed more distant affinities to the mt DNA, perhaps generated by inter-organelle transfer and integration.

Table 3 Summary of gene translation studies for perA gene

\begin{tabular}{ccc}
\hline $\begin{array}{c}\text { Endophyte } \\
\text { taxon }\end{array}$ & $\begin{array}{c}\text { Predicted } \\
\text { functional } \\
\text { gene copies }\end{array}$ & $\begin{array}{c}\text { Results of gene translation } \\
\text { relation to proposed } \\
\text { progenitor origin }\end{array}$ \\
\hline N. coenophialum & $2(3)$ & E. f (F), E. t (F), FGC1 (NF) \\
FaTG-2 & $1(2)$ & E. $f(F), F G C 1(N F)$ \\
FaTG-3 & $1(2)$ & E. t (F), FGC1 (NF) \\
FaTG-3-like & $1(2)$ & E. t (F), FGC1 (NF) \\
UNS & $0(2)$ & E. f (NF), FGC1 (NF) \\
N. uncinatum & $1(2)$ & E. t (F), E.br (NF)
\end{tabular}

Note: Total number of gene copies identified for each taxon is given in brackets next to the number of proposed functional gene copies. E. $f=E$. festucae, $\mathrm{E} . \mathrm{t}=\mathrm{E}$. typhina, $\mathrm{FGC1}=$ Fescue gene copy 1 , E. $\mathrm{br}=$ E. bromicola, $\mathrm{F}=$ predicted functional gene, $\mathrm{NF}=$ predicted non-functional gene. 
Table 4 Comparison of $\mathrm{mt}$ genomes of analysed endophytes

\begin{tabular}{|c|c|c|c|c|c|c|}
\hline \multirow{2}{*}{$\begin{array}{l}\text { Sample } \\
\text { name }\end{array}$} & \multirow{2}{*}{$\begin{array}{l}\text { Endopphyte } \\
\text { taxon }\end{array}$} & \multirow{2}{*}{$\begin{array}{l}\text { Number } \\
\text { of contigs } \\
\text { assembled }\end{array}$} & \multirow[t]{2}{*}{ Coverage } & \multicolumn{3}{|c|}{ Mt Genome } \\
\hline & & & & Total length (bp) & $\begin{array}{c}\% \text { protein gene } \\
\text { content }\end{array}$ & $\begin{array}{l}\% \text { ID within protein } \\
\text { gene content }\end{array}$ \\
\hline NC008068 & M. anisopliae & N/A & N/A & 24673 & 59.11 & - \\
\hline NEA22 & N. coenophialum & 4 & $>800$ & 93,968 & 15.52 & 90.7 \\
\hline NEA14 & N. coenophialum & 5 & $>900$ & 94,628 & 15.41 & 90.5 \\
\hline NEA16 & N. coenophialum & 1 & $>1800$ & 95,628 & 15.25 & 90.9 \\
\hline NEA20 & N. coenophialum & 5 & $>1700$ & 94,924 & 15.36 & 90.7 \\
\hline E34 & N. coenophialum & 4 & $>2100$ & 95,719 & 15.24 & 90.9 \\
\hline NEA18 & UNS & 4 & $>1200$ & 82,857 & 17.60 & 91.0 \\
\hline NEA19 & UNS & 1 & $>2400$ & 83,619 & 17.44 & 90.7 \\
\hline NEA23 & FaTG-3 & 4 & $>2800$ & 91,949 & 15.86 & 90.7 \\
\hline NEA21 & FaTG-3 & 1 & $>700$ & 91,820 & 15.88 & 90.8 \\
\hline 598829 & FaTG-3 like & 1 & $>2500$ & 79,875 & 18.26 & 90.8 \\
\hline NEA17 & FaTG-2 & 2 & $>1200$ & 95,822 & 15.22 & 91.2 \\
\hline 598852 & FaTG-2 & 4 & $>3800$ & 96,481 & 15.12 & 91.2 \\
\hline E81 & N. uncinatum & 3 & $>970$ & 84,718 & 17.22 & 90.6 \\
\hline 9636 & E. typhina & 1 & $>2600$ & 85,030 & 17.15 & 90.6 \\
\hline 9340 & E. typhina & 2 & $>2500$ & 51,884 & 28.11 & 90.5 \\
\hline \multirow[t]{2}{*}{9707} & E. baconii & 1 & $>1400$ & 61,133 & 23.86 & 89.9 \\
\hline & E. festucae & N/A & N/A & 69696 & 20.93 & 91.1 \\
\hline SE & N. Iolii & N/A & N/A & 88738 & 16.44 & 91.0 \\
\hline NEA11 & LpTG-2 & N/A & N/A & 88810 & 16.42 & 91.1 \\
\hline
\end{tabular}

\section{Phylogenetic relationships based on mitochondrial genome comparisons}

Phylogenetic relationships were reconstructed based on the concatenated sequences of 13 mitochondrial proteincoding genes from the fescue endophytes, while the equivalent for M. anisopliae was used as the out-group (Figure 6). Similar tree topology was observed for parsimony, ML and NJ methods (related alignments can be found at URL: http://purl.org/phylo/treebase/phylows/study/TB2:S14923). As expected, individual sequences from the same taxon clustered together. A number of putative progenitor relationships, such as that between E. typhina and $N$ uncinatum, were more readily apparent from the phylogram. Close relationships were revealed between the $N$. lolii and $L p$ TG-2 mt genomes and that of their putative sexual progenitor, E. festucae, and similar, but less close, relationships were apparent for $N$. coenophialum and FaTG-2. Commonalities of mitochondrial genome structure were evident between the FaTG-3 and FaTG-3-like mt genomes, albeit with lower bootstrap support, but affinity to potential Epichloë genomes was not so obvious, although an E. festucae mt genome provides the most obvious candidate. This result was inconsistent with the data from the nuclear gene analyses in the present study, that revealed closer relationships of gene copies from the FaTG-3 and FaTG-3-like isolates to the putative FGC1 progenitor, and to E. typhina. A clear differentiation of the UNS mt genome from that of the preceding groups, with higher levels of sequence similarity to E. baconii and E. typhina rather than E. festucae, was evident from this analysis.

\section{Discussion}

The results obtained in the present study have confirmed the accuracy of previous assignment of endophyte accessions to distinct known taxonomic groups based on SSR polymorphism, along with the definition of several putative novel taxa [9]. The prior study was only capable of performing phenetic classification, but analysis of individual nuclear gene sequences has further permitted exploration of genome complexity within the heteroploid endophyte taxa, as well as interpretation of relationships with contemporary Epichloë species as representatives of putative progenitors.

Following the assembly of Illumina HiSeq2000 short reads utilising the Velvet assembly algorithm it was observed that large number of contigs were generated for heteroploid fescue grass-derived endophyte genomes (see assembly statistics listed in Additional file 7). This observation indicated that although Velvet is well-suited to assembly of haploid genomes, is not so appropriate for 


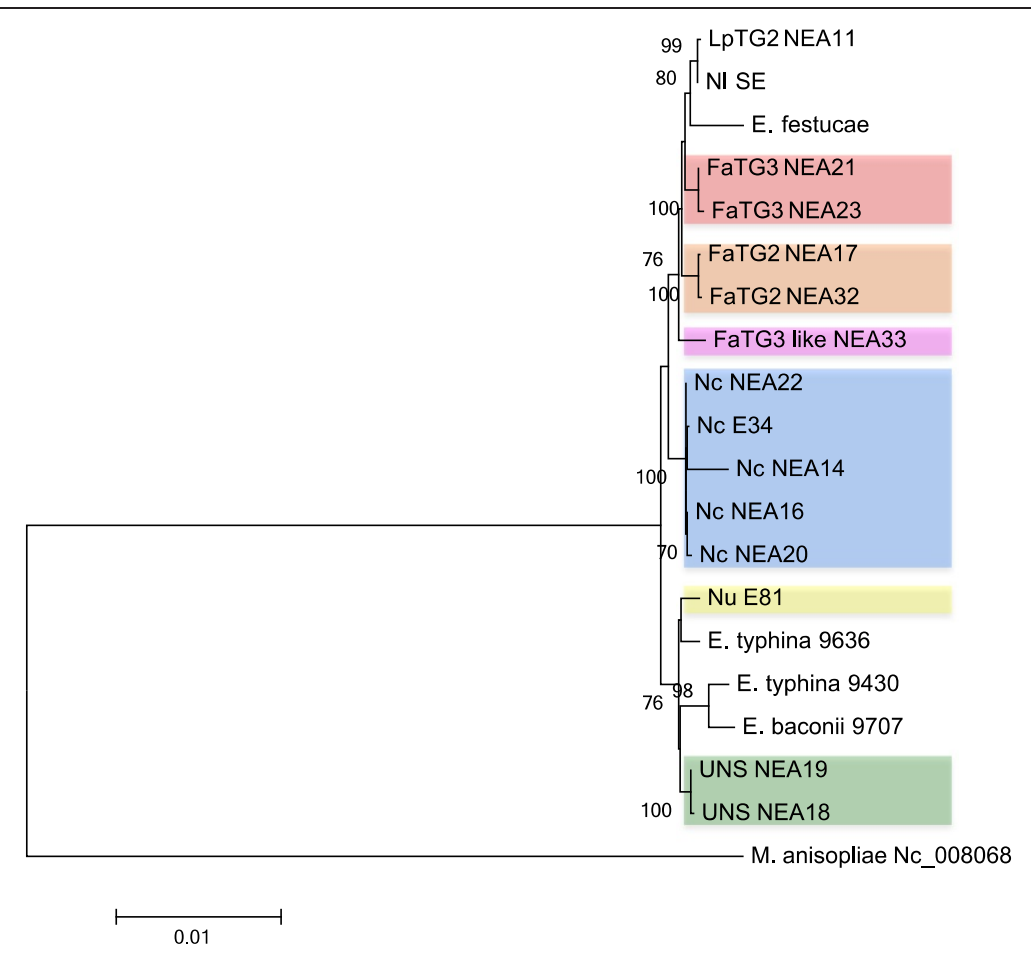

Figure 6 Bootstrap consensus tree generated through maximum likelihood analysis of concatenated protein-coding gene sequences within the mitochondrial genomes of reference endophyte isolates and selected fescue endophytes. Diagram properties are as described for Figure 2. The tree was rooted by addition of the mt genome protein-coding gene complement of Metarhizium anisopliae.

heteroploid genomes. Furthermore, in those instances characterised by multiple gene copies, Velvet was incapable of constructing the individual gene copies using short reads. However, the number of assembled contigs was sufficient to indicate the number of gene copies, and when evidence for multiple copies was obtained, individual genes were accurately assembled by a manual process.

\section{Copy number variation of selected nuclear genes}

The presence of 3 copies for each of the tefA, tub2 and perA genes in the $N$. coenophialum genome suggests a tri-parental hybrid origin, consistent with previous studies $[17,23]$. Similarly, the observation of 2 copies for each gene in the genomes of other heteroploid endophyte taxa (FaTG-2, FaTG-3, FaTG-3-like and UNS) is compatible with a series of bi-parental hybrid origins. Although $N$. uncinatum has also previously been inferred to have arisen as a bi-parental hybrid, the presence of a sole tub2 gene copy suggests selective gene loss, as previously proposed to account for the current heteroploid constitution of this and other taxa. These results, apart from concordance with earlier sequence-based studies $[14,19]$, are also consistent with the complexity of SSR profiles from the same accessions [9], which typically contained up to 3 distinct amplicons from $N$. coenophialum genotypes, and up to 2 amplicons from the other taxa in this study.

\section{Phylogeny of previously described fescue-derived endophytes}

The present study has also permitted identification of those Epichloë species that are likely to be most closely related to the taxa that participated in hybrid origins. Previous phylogenetic studies based on two of the nuclear genes used in this study (tub2 and tefA), as well as the act 1 actin gene, have provided evidence for progenitor identity [15]. Three tall fescue-derived endophyte taxa have previously been included in such studies, N. coenophialum was proposed to have originated from E. festucae-, E. baconii- and E. typhina-like ancestors [18,19,42], while FaTG-2 and FaTG-3 were suggested to be derived from E. festucae- and E. baconii-like, and E. baconii- and E. typhina-like ancestors, respectively [17]. As summarised in Figure 7, the present study was consistent with these predictions in terms of affinities to contemporary E. festucae and E. typhina genotypes, but more distant relationships were observed for E. baconii. The group designated FGC1 in this study, which cannot be unequivocally attributed to a $E$. baconii-like progenitor, was also identified in a previous study and termed the 'Lolium-associated endophyte' (LAE) clade [23,43]. Furthermore, two distinct $E$. typhina lineages appear to have contributed to formation of the $N$. coenophialum/N. uncinatum and FaTG-3/FaTG3-like heteroploid genomes, respectively (Figure 7), based on interpretation of the tree and network diagrams. 


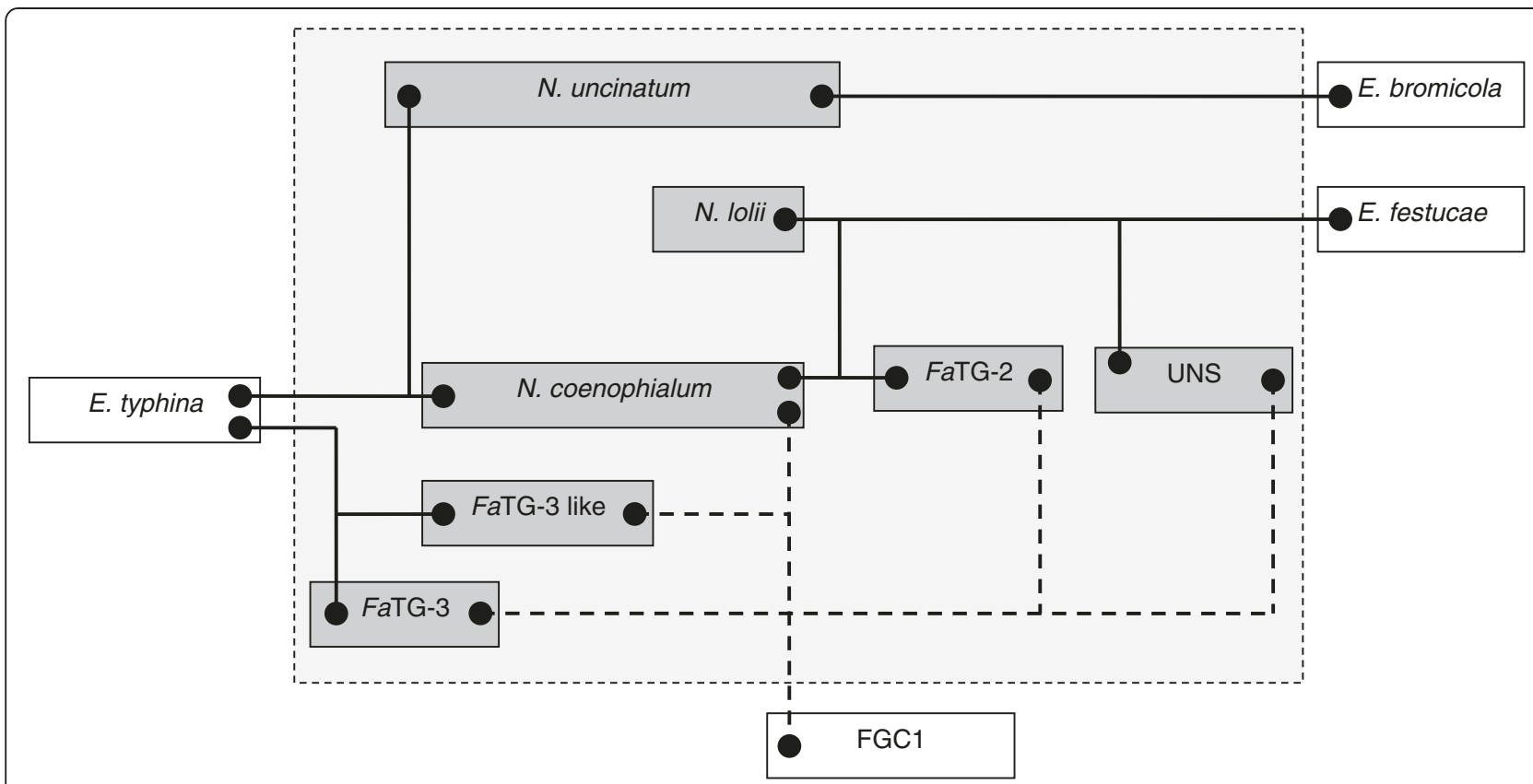

Figure 7 Summary of nuclear genome affinities between endophyte taxa. In the graphic, proposed progenitors are represented as species outside the box. Solid lines indicate the clear relationships with characterised progenitor species, while lower confidence relationships to uncharacterised progenitors are marked by dashed lines.

Phylogenetic reconstruction based on the perA gene sequence revealed a closer relationship between $E$. amarillans and the FGC1 than for the E. baconii genotype that was used in this study. However, the E. amarillans-derived tefA gene sequence demonstrated a close genetic relationship to $E$. baconii, and $E$. amarillans formed a sub-clade with $E$. baconii, E. festucae, and N. lolii as well the FGC1 clade, consistent with previous studies [43]. Observed anomalies between the gene-specific phylogenies in the present study may be due to different rates of molecular evolution between endophyte-specific (perA) and housekeeping (tefA and $t u b 2$ ) genes. Further to this, addition of the entire tefA gene sequences of $E$. amarillans to the phylogenetic analysis may provide a higher level of resolution.

\section{Phylogeny of mt genomes}

For N. coenophialum, FaTG-2 and FaTG-3, the mitochondrial gene complement-based analysis revealed closest relationships to E. festucae, suggesting that this or a closely related sexual species donated the cytoplasmic genome to the known heteroploid taxa. This conclusion is again consistent with previous studies, apart from the status of FaTG-3, which does not show strong similarity to the mt genomes of either E. baconii or E. typhina. This anomaly may be due to the effects of recombination between progenitor mitochondrial genomes following generation of a heteroplasmon by parasexual processes [24]. Such mechanisms have been demonstrated to operate in sexual crosses between E. typhina endophytes, although in general, uniparental inheritance is observed [44]. Alternatively, accelerated evolutionary rates of mt DNA relative to nuclear DNA, which have been observed in animals, fungi and in certain protist species [27], may contribute to lower phylogenetic affinities. In support of this explanation, substantial size differences were observed between the mt genomes of the two E. typhina isolates used for this study, suggesting that extensive surveys of intraspecific diversity may be required to identify suitable candidates for progenitor status. However, mt genomes within a given heteroploid taxon were relatively uniform in size, suggesting that limited opportunities for evolutionary divergence have arisen.

In contrast, the $N$. uncinatum mt genome protein coding gene complement is very closely related to that of one E. typhina lineage, consistent with an origin from this species during heteroploid formation. Furthermore, the mt genome of $L p \mathrm{TG}-2$, which was inferred to have arisen as an N. lolii x E. typhina hybrid [45], demonstrates a high genetic similarity to the $N$. lolii $\mathrm{mt}$ genome, as confirmed by previous studies $[37,46]$. This latter observation suggests a relatively recent origin in evolutionary time, and the absence of complicating factors such as recombination between $\mathrm{mt}$ genomes.

\section{Phylogeny of novel fescue-derived endophytes}

A close relationship was apparent between the previously described taxon FaTG-2 and the novel UNS endophyte group, both of which show affinities to E. festucae 
and to the putative progenitor of the FGC1/LAE lineages. This result was consistent with the SSR-based phenetic analysis, in which FaTG-2 and UNS accessions were located in sister groups within the same supercluster of the phenogram [9]. Despite this close affinity, the present study was able to confirm that these two taxa are distinct, based on the formation of separate sub-clusters in both the FGC1 and Group 1 E. festucaecontaining clades of the phylograms, as well as in the network diagram. The $\mathrm{mt}$ genome phylogram reinforced this distinction, suggesting that the UNS mt genome may have been contributed by the ancestor of the FGC1/LAE lineages, while the FaTG-2 mt genome, as previously described, is most closely related to E. festucae. In combination, the data suggests that these two heteroploid taxa may be derived from hybridisation events in reciprocal mode between two pairs of closely related haploid species, or that divergence from common origins has occurred within each lineage.

Similarly, close relationships between the FaTG-3 and FaTG-3-like endophytes was revealed through the initial endophyte-specific SSR analysis [9]. In the present study, both FaTG-3 and FaTG-3-like endophytes display phylogenetic affinities to both E. typhina and the FGC1/LAE ancestor, with particularly strong similarity for the $E$. typhina-like gene copies. Similar relationships have been obtained for FaTG-3-like endophytes (later designated as FaTG-4) in a previous study of tub2 phylogeny [14]. Furthermore, both groups also showed E. festucae-like mt genome structure. However, the two groups were identified in differing host grass taxa, FaTG-3 genotypes being detected in Mediterranean hexaploid tall fescue accessions, while FaTG-3-like endophytes were obtained from decaploid tall fescue [9]. At the genomic level, commonly observed deletions of the FGC1/LAE perA gene copy in FaTG-3 were not present in the FaTG-3-like endophytes. In general, the FGC1 copies of each nuclear gene were distinct between FaTG-3 and FaTG-3-like endophytes, suggesting origin of this genomic sub-component from related but distinct taxa.

\section{Variation of nuclear gene structure}

Previous phylogenetic studies of tub2, tefA, act 1 and several alkaloid biosynthesis genes, including perA were performed by PCR amplification and subsequent sequencing of amplified PCR products $[17,21,23]$. More recently, a study of tub2 phylogeny made partial use of whole genome sequence data [13]. In contrast, the present study was solely based on whole genome sequencing and subsequent independent assembly of entire tub2,tefA, and perA genes, allowing comprehensive identification of insertiondeletion events. Two common deletions were identified in the FGC1-specific perA gene copies from FaTG-2, FaTG3 and UNS endophytes. A previous study of perA gene phylogeny reported the presence of a 328 bp deletion within the coding region of the FaTG-2 genome [23], similar to observations of the FaTG-2, FaTG-3 and UNS genomes in this study, and an additional adjacent deletion of $627 \mathrm{bp}$ within the same gene copy was here identified for all three taxa. As FaTG-2 endophytes have previously been demonstrated to effectively produce the alkaloid, perA gene function must be due not to the FGC-1 gene copy, but the alternate copy that is putatively derived from an E. festucae-like progenitor.

In addition to these structural changes, the perA sequence of $E$. baconii endophyte 9707 exhibited an identical deletion to that reported in the E. festucae endophyte E2368 [47], through loss of the reductase domainencoding sequence at the 3 '-terminus. Although this deletion is common among endophytes [3] none of the sequenced novel fescue endophytes were found to contain this deletion.

\section{Conclusion}

Complex and highly reticulated evolutionary relationships between Epichloë-Neotyphodium endophytes have been predicted on the basis of multiple nuclear genes and entire mitochondrial protein-coding gene sequences derived from independent assembly of whole genome sequence reads. Furthermore, results from the present study have confirmed the distinct status of the novel fescue endophyte taxa FaTG-3-like and UNS [9]. The designation of the FaTG-3-like taxon as FaTG-4, as proposed in a recent sequence-based phylogenomics analysis [14], is supported by the data presented here. For consistency, it is therefore also proposed that UNS is henceforth designated as FaTG-5. Apart from fundamental implications for evolutionary processes, the present study has provided information and resources for detection, discrimination and potential modification of agronomically important endophyte taxa.

\section{Availability of supporting data}

The data sets supporting the results of this article are included within the article and its additional files. Nuclear protein-coding sequences and the reference $\mathrm{N}$. lolii $\mathrm{mt}$ DNA sequence have been deposited in GenBank. Sequence alignments of mitochondrial protein-coding genes have been deposited in TreeBASE at URL: http://purl.org/ phylo/treebase/phylows/study/TB2:S14923.

\section{Additional files}

Additional file 1: Bootstrap consensus tree generated through parsimony analysis of tub2 gene sequence among extended set of reference endophyte isolates and selected fescue endophytes.

Branches with bootstrap values of greater than $70 \%$ from 1000 bootstrap replication are marked next to each branch. Endophyte taxa are colour 
coded as indicated in the legend. Endophyte taxon abbreviation prior to isolate name are as follows: $\mathrm{Nc}=\mathrm{N}$. coenophialum, $\mathrm{Nu}=\mathrm{N}$. uncinatum, UNS = uncharacterised Neotyphodium species.

Additional file 2: Phylogram obtained for parsimony analysis of concatenated gene sequences of tub2, tefA and perA among reference endophyte isolates and selected fescue endophytes. Branches with bootstrap values of greater than $70 \%$ from 1000 bootstrap replication are marked next to each branch. Endophyte taxon abbreviations prior to isolate name are as follows: $\mathrm{Nc}=\mathrm{N}$. coenophialum, $\mathrm{Nu}=\mathrm{N}$. uncinatum, UNS $=$ uncharacterised Neotyphodium species.

Additional file 3: Bootstrap consensus tree generated through maximum likelihood analysis of tub2 gene sequence among reference endophyte isolates and selected fescue endophytes. Branches with bootstrap values of greater than $70 \%$ from 1000 bootstrap replication are marked next to each branch.

Additional file 4: Bootstrap consensus tree generated through maximum likelihood analysis of tef $A$ gene sequence among reference endophyte isolates and selected fescue endophytes. Branches with bootstrap values of greater than 70\% from 1000 bootstrap replication are marked next to each branch.

Additional file 5: Bootstrap consensus tree generated through maximum likelihood analysis of perA gene sequence among reference endophyte isolates and selected fescue endophytes. Branches with bootstrap values of greater than $70 \%$ from 1000 bootstrap replication are marked next to each branch.

Additional file 6: Genbank accession numbers of the sequences represented in the phylogenetic study.

Additional file 7: Sequence output and de novo assembly statistics for sequenced fescue-derived endophytes.

\section{Competing interests}

The authors declare that they have no competing interests.

\section{Authors' contributions}

PNE carried out the DNA extractions, generation of the DNA sequences, performed the phylogenetic analysis and drafted the manuscript. MR performed sequence analysis and assembly of the N.Iolii SE mt genome. TIS KMG, JWF and GCS co-conceptualised and coordinated the project, contributed to data interpretation and assisted in drafting the manuscript. All authors read and approved the final manuscript.

\section{Acknowledgements}

This work was supported by funding from the Victorian Department of Environment and Primary Industries, the Royal Barenbrug Group, Netherlands, and the Dairy Futures Cooperative Research Centre.

\section{Author details}

'Department of Environment and Primary Industries, Biosciences Research Division, AgriBio, the Centre for AgriBioscience, 5 Ring Road, Bundoora, Victoria 3086, Australia. ${ }^{2}$ Dairy Futures Cooperative Research Centre, Bundoora, Australia. ${ }^{3}$ La Trobe University, Bundoora, Victoria 3086, Australia.

Received: 17 July 2013 Accepted: 6 December 2013

Published: 12 December 2013

\section{References}

1. Arachevaleta M, Bacon CW, Hoveland CS, Radcliffe DE: Effect of the tall fescue endophyte on plant response to environmental stress. Agron J 1989, 81:83-90.

2. Malinowski DP, Belesky DP: Adaptations of endophyte-infected coolseason grasses to environmental stresses: mechanisms of drought and mineral stress tolerance. Crop Sci 2000, 40:923-940.

3. Schardl CL, Young CA, Faulkner JR, Florea S, Pan J: Chemotypic diversity of epichloae, fungal symbionts of grasses. fungal ecology 2012, 5:331-344.

4. Siegel MR, Latch GCM, Bush LP, Fannin FF, Rowan DD, Tapper BA, Bacon CW, Johnson MC: Fungal endophyte-infected grasses: alkaloid accumulation and aphid response. J Chem Ecol 1990, 16(12):3301-3315.
5. Schardl CL, Grossman RB, Nagabhyru P, Faulkner JR, Mallik UP: Loline alkaloids: currencies of mutualism. Phytochemistry 2007, 68:980-996.

6. Tanaka A, Tapper BA, Popay A, Parker EJ, Scott B: A symbiosis expressed non-ribosomal peptide synthetase from a mutualistic fungal endophyte of perennial ryegrass confers protection to the symbiotum from insect herbivory. Mol Microbiol 2005, 57(4):1036-1050.

7. Gallagher RT, Hawkes AD, Steyn PS, Vleggaar R: Tremorgenic neurotoxins from perennial ryegrass causing ryegrass staggers disorder of livestock: structure elucidation of lolitrem B. J Chem Soc Chem Commun 1984, 9:614-616.

8. Porter JK: Analysis of endophyte toxins - Fescue and other grasses toxic to livestock. J Anim Sci 1995, 73(3):871-880.

9. Ekanayake PN, Hand ML, Spangenberg GC, Forster JW, Guthridge KM: Genetic diversity and host specificity of fungal endophyte taxa in fescue pasture grasses. Crop Sci 2012, 52:2243-2252.

10. Hand ML, Cogan NOI, Forster JW: Molecular characterisation and interpretation of genetic diversity within globally distributed germplasm collections of tall fescue (Festuca arundinacea Schreb.) and meadow fescue (F. pratensis Huds.). Theor App/ Genet 2012, 124:1127-1137.

11. Hand M, Cogan N, Stewart A, Forster J: Evolutionary history of tall fescue morphotypes inferred from molecular phylogenetics of the LoliumFestuca species complex. BMC Evol Biol 2010, 10(1):303.

12. Glenn AE, Bacon CW, Price R, Hanlin RT: Molecular phylogeny of Acremonium and its taxonomic implications. Mycologia 1996, 88(3):369-383.

13. Christensen MJ, Leuchtmann A, Rowan DD, Tapper BA: Taxonomy of Acremonium endophytes of tall fescue (Festuca arundinacea), meadow fescue (F. pratensis) and perennial ryegrass (Lolium perenne). Mycol Res 1993, 97(9):1083-1092.

14. Schardl C, Young C, Pan J, Florea S, Takach J, Panaccione D, Farman M, Webb J, Jaromczyk J, Charlton N, et al: Currencies of mutualisms: sources of alkaloid genes in vertically transmitted epichloae. Toxins 2013, 5(6):1064-1088.

15. Craven KD, Blankenship JD, Leuchtmann A, Hignight K, Schardl CL: Hybrid fungal endophytes symbiotic with the grass Lolium pratense. Sydowia 2001, 53(1):44-73.

16. Moon CD, Scott B, Schardl CL, Christensen MJ: The evolutionary origins of Epichloë endophytes from annual ryegrasses. Mycologia 2000, 92(6):1103-1118.

17. Moon CD, Craven KD, Leuchtmann A, Clement SL, Schardl CL: Prevalence of interspecific hybrids amongst asexual fungal endophytes of grasses. Mol Ecol 2004, 13:1455-1467.

18. Tsai HF, Liu JS, Staben C, Christensen MJ, Latch GCM, Siegel MR, Schardl CL: Evolutionary diversification of fungal endophytes of tall fescue grass by hybridization with Epichloë species. Proc Natl Acad Sci USA 1994 91(7):2542-2546.

19. van Zijll de Jong E, Guthridge KM, Spangenberg GC, Forster JW: Sequence analysis of SSR-flanking regions identifies genome affinities between pasture grass fungal endophyte taxa. Int J Evol Biol 2011. Article ID 921312, 11 pages, doi:10.4061/2011/921312.

20. Gentile A, Rossi MS, Cabral D, KC D, Schardl CL: Origin, divergence, and phylogeny of Epichloë endophytes of native Argentine grasses. Mol Phylogenet Evol 2005, 35:196-208.

21. Craven KD, Hsiau PTW, Leuchtmann A, Hollin W, Schardl CL: Multigene phylogeny of Epichloë species, fungal symbionts of grasses. Ann Mo Bot Gard 2001, 88(1):14-34.

22. Schardl CL, Young CA, Hesse U, Amyotte SG, Andreeva K, Calie PJ, Fleetwood DJ, Haws DC, Moore N, Oeser B, et al: Plant-symbiotic fungi as chemical engineers: multi-genome analysis of the clavicipitaceae reveals dynamics of alkaloid Loci. PLOS Genet 2013, 9(2):28.

23. Takach JE, Mittal S, Swoboda GA, Bright SK, Trammell MA, Hopkins AA, Young CA: Genotypic and chemotypic diversity of Neotyphodium endophytes in tall fescue from Greece. Appl Environ Microbiol 2012, 78:5501-5510.

24. Griffiths AJF: Mitochondrial inheritance in filamentous fungi. J Genet 1996, 75:403-414.

25. Gray MW, Burger G, Lang BF: Mitochondrial evolution. Science 1999 283(5407):1476-1481.

26. Gray MW: Mitochondrial evolution. Cold Spring Harb Perspect Biol 2012, 4:9.

27. Burger G, Gray MW, Franz Lang B: Mitochondrial genomes: anything goes. Trends Genet 2003, 19(12):709-716.

28. Möller EM, Bahnweg G, Sandermann H, Geiger HH: A simple and efficient protocol for isolation of high molecular weight DNA from filamentous fungi, fruit bodies and infected plant tissue. Nucleic Acids Res 1992, 20(22):6115-6116 
29. Zerbino DR, Birney E: Velvet: algorithms for de novo short read assembly using de Bruijn graphs. Genome Res 2008, 18(5):821-829.

30. Altschul S, Gish W, Miller W, Myers E, Lipman D: Basic local alignment search tool. J Mol Biol 1990, 215(3):403-410.

31. Manolo G, Stéphane G, Olivier G: SeaView Version 4: a multiplatform graphical user interface for sequence alignment and phylogenetic tree building. Mol Biol Evol 2010, 27(2):221-224.

32. Artimo P, Jonnalagedda M, Arnold K, Baratin D, Csardi G, De Castro E, Duvaud S, Flegel V, Fortier A, Gasteiger E, et al: ExPASy: SIB bioinformatics resource portal. Nucleic Acids Res 2012, 40:W597-W603.

33. Larkin MA, Blackshields G, Brown NP, Chenna R, McGettigan PA, McWilliam $H$, Valentin F, Wallace IM, Wilm A, Lopez R, et al: ClustalW and ClustalX version 2. Bioinformatics 2007, 23(21):2947-2948.

34. Tamura K, Peterson D, Peterson N, Stecher G, Nei M, Kumar S: MEGA5: molecular evolutionary genetics analysis using maximum likelihood, evolutionary distance, and maximum parsimony methods. Mol Biol Evol 2011, 28:2731-2739

35. Bryant $\mathrm{D}$, Moulton V: NeighborNet: an agglomerative algorithm for the construction of phylogenetic networks. Mol Biol Evol 2004, 21:255-265.

36. Huson D, Bryant D: Application of phylogenetic networks in evolutionary studies. Mol Biol Evol 2006, 23:254-267.

37. Rabinovich M: Genome structure and diversity in the perennial ryegrass (Lolium perenne l.) fungal endophyte Neotyphodium Iolii. Bundoora: La trobe University; 2011.

38. Li H, Durbin R: Fast and accurate short read alignment with BurrowsWheeler Transform. Bioinformatics 2009, 25:1754-1760

39. Milne I, Bayer M, Cardle L, Shaw P, Stephen G, Wright F, Marshall D: Tablet next generation sequence assembly visualization. Bioinformatics 2010, 26(3):401-402.

40. Brudno M, Do CB, Cooper GM, Kim MF, Davydov E, Green ED, Sidow A, Batzoglou S: NISC Comparative Sequencing Program. LAGAN and MultiLAGAN: efficient tools for large-scale multiple alignment of genomic DNA. Genome Res 2003, 13(4):721-731.

41. Frazer KA, Pachter L, Poliakov A, Rubin EM, I. D: VISTA: computational tools for comparative genomics. Nucleic Acids Res 2004, 1(32):W273-279.

42. Moon CD, Miles CO, Jarlfors U, Schardl CL: The evolutionary origins of three new Neotyphodium endophyte species from grasses indigenous to the Southern Hemisphere. Mycologia 2002, 94(4):694-711.

43. Schardl CL, Craven KD, Speakman S, Stromberg A, Lindstrom A, Yoshida R: A novel test for host-symbiont codivergence indicates ancient origin of fungal endophytes in grasses. Syst Biol 2008, 57(3):483-498.

44. Chung KR, Leuchtmann A, Schardl CL: Inheritance of mitochondrial DNA and plasmids in the ascomycetous fungus, Epichloë typhina. Genetics 1996, 142(1):259-265.

45. Kuldau GA, Tsai HF, Schardl CL: Genome sizes of Epichloë species and anamorphic hybrids. Mycologia 1999, 91(5):776-782.

46. Schardl CL, Leuchtmann A, Tsai HF, Collett MA, Watt DM, Scott DB: Origin of a fungal symbiont of perennial ryegrass by interspecific hybridization of a mutualist with the ryegrass choke pathogen, Epichloë typhina. Genetics 1994, 136(4):1307-1317.

47. Fleetwood DJ, Khan AK, Johnson RD, Young CA, Mittal S, Wrenn RE, Hesse U, Foster SJ, Schardl CL, B. S: Abundant degenerate miniature inverted-repeat transposable elements in genomes of epichloid fungal endophytes of grasses. Genome Biol Evol 2011, 3:1253-1264.

doi:10.1186/1471-2148-13-270

Cite this article as: Ekanayake et al.: Phylogenomics of fescue grassderived fungal endophytes based on selected nuclear genes and the mitochondrial gene complement. BMC Evolutionary Biology 2013 13:270. 